\title{
Guest editorial: fanconi anemia and the DNA damage response
}

\author{
Minoru Takata
}

Received: 2 March 2011/Revised: 8 March 2011/Accepted: 22 March 2011/Published online: 12 April 2011

(c) The Japanese Society of Hematology 2011

Every cell in our body other than red blood cells has a genome, the stability of which is crucial for life. The DNA is precisely replicated during cell proliferation, and is stably maintained, even after terminal differentiation, as a repository of information that orchestrates the cell's metabolism. Unfortunately, our world is full of potential threats to genomic stability. DNA may degrade spontaneously, errors may occur during its replication, or metabolic byproducts, such as oxygen radicals or aldehydes, may chemically modify its nucleotide bases (i.e. DNA adducts). Ionizing radiation, ultraviolet light, and chemotherapeutic drugs are all well-known exogenous sources of DNA damage $[1,2]$.

To ensure cellular fitness, organisms have developed an elaborate molecular network to detect and repair DNA damage [3]. If deleterious effects of DNA damage exceed the cell's repair capacity, it accumulates in the genome, leading to activation of cell cycle checkpoints (buying time for repair), cell death (apoptosis or necrosis), or, in the failure of checkpoints or cell death, conversion of DNA damage to mutations. This may result in poor cell proliferation, emergence of malignancy, impaired stem cell maintenance, or early-onset aging $[1,2]$. Since all cellular activity in a way relies on the genome, the mechanisms that govern genomic stability are fundamentally important in biomedical research in general. Blood cells are no exception.

As our knowledge of genomic stability has expanded massively in recent years, a rare hematological disorder,

\section{Takata ( $\square)$}

Laboratory of DNA Damage Signaling,

Department of Late Effect Studies,

Radiation Biology Center, Kyoto University, Kyoto, Japan

e-mail: mtakata@house.rbc.kyoto-u.ac.jp
Fanconi anemia (FA), has become a prototypical example among hereditary conditions involving a defect in the DNA damage response (DDR). FA is one of several disorders discovered by the prominent Swiss pediatrician Guido Fanconi [4]. His first report in 1927 described brothers presenting with a pernicious anemia-like condition, congenital anomalies, and hyper-pigmentation of the skin. In the 1960s and 70s, it was established that FA cells display chromosomal instability, which is particularly pronounced following treatment with mitomycin $\mathrm{C}[5,6]$. The first molecular cloning of an FA gene was achieved by functional complementation using a cDNA expression library in the early 1990s [7]. However, until quite recently, the true molecular defect in FA, which is now considered to affect the response to replication stress, had not been defined.

There seem to be a number of reasons why FA attracts widespread attention today. First of these is that novel FA genes continue to be identified year after year. This trend began at the turn of the 21 st century, and has continued into this year, with the current number of the FA genes now totaling 15 [8-10]. This is surprising. Second, FA patients with disparate mutations display essentially similar phenotypes, strongly suggesting the presence of a common signal transduction pathway consisting of the FA gene products (i.e. FA pathway) [11, 12]. This prediction was well confirmed by the identification of the FA core complex (i.e. interactions between the FA core components FANCA/B/C/E/F/G/M/L) as an E3 ubiquitin ligase, and DNA damage-induced monoubiquitination of FANCD2 and FANCI, which is absent in cells lacking the core complex members [11, 12]. Of note, posttranslational protein modifications, such as ubiquitination, are currently the focus of intensive research in this field [13, 14]. Third, the discovery that the FANCD1 gene is the breast cancer 
suppressor BRCA2 has had an enormous impact [15]. This means that the FA pathway has a strong connection with the much more common disease, familial breast cancer. Fourth, hematopoietic stem cells are affected in FA. Thus, it is perhaps not unexpected that FA is one of the first disorders for which patient-derived induced pluripotent stem (iPS) cells have been generated [16]. In addition to the above, there are numerous other very interesting studies of FA that I cannot mention here.

To provide some perspective on FA and the DNA damage response, this issue of IJH publishes a set of review articles as part of the "Progress of Hematology" series. In addition to our own account of FA, this collection contains up-to-date summaries regarding the maintenance of hematopoietic stem cells and the DNA damage response, the exciting discovery of the BLM helicase-FA relationship in ultrafine chromosomal bridges, and the molecular mechanisms, such as ubiquitination, that are activated in response to DNA double strand breaks, and their dysfunction in primary immunodeficiency syndromes. I trust our readers will find these reviews to be interesting, and useful in their work.

\section{References}

1. Hoeijmakers JH. Genome maintenance mechanisms for preventing cancer. Nature. 2001;411:366-74.

2. Rouse J, Jackson SP. Interfaces between the detection, signaling, and repair of DNA damage. Science. 2002;297:547-51.
3. Harper JW, Elledge SJ. The DNA damage response: ten years after. Mol Cell. 2007;28:739-45.

4. Lobitz S, Velleuer E. Guido Fanconi (1892-1979): a jack of all trades. Nat Rev Cancer. 2006;6:893-8.

5. Sasaki MS, Tonomura A. A high susceptibility of Fanconi's anemia to chromosome breakage by DNA cross-linking agents. Cancer Res. 1973;33:1829-36.

6. Sasaki MS. Is Fanconi's anaemia defective in a process essential to the repair of DNA cross links? Nature. 1975;257:501-3.

7. Strathdee CA, Gavish H, Shannon WR, Buchwald M. Cloning of cDNAs for Fanconi's anaemia by functional complementation. Nature. 1992;356:763-7.

8. Crossan GP, van der Weyden L, Rosado IV, et al. Disruption of mouse $\mathrm{Slx} 4$, a regulator of structure-specific nucleases, phenocopies Fanconi anemia. Nat Genet. 2011;43:147-52.

9. Kim Y, Lach FP, Desetty R, Hanenberg H, Auerbach AD, Smogorzewska A. Mutations of the SLX4 gene in Fanconi anemia. Nat Genet. 2011;43:142-6.

10. Stoepker C, Hain K, Schuster B, et al. SLX4, a coordinator of structure-specific endonucleases, is mutated in a new Fanconi anemia subtype. Nat Genet. 2011;43:138-41.

11. Wang W. Emergence of a DNA-damage response network consisting of Fanconi anaemia and BRCA proteins. Nat Rev Genet. 2007;8:735-48.

12. Kee Y, D'Andrea AD. Expanded roles of the Fanconi anemia pathway in preserving genomic stability. Genes Dev. 2010; 24:1680-94.

13. Cohn MA, D'Andrea AD. Chromatin recruitment of DNA repair proteins: lessons from the fanconi anemia and double-strand break repair pathways. Mol Cell. 2008;32:306-12.

14. Huang TT, D'Andrea AD. Regulation of DNA repair by ubiquitylation. Nat Rev Mol Cell Biol. 2006;7:323-34.

15. Howlett NG, Taniguchi T, Olson S, et al. Biallelic inactivation of BRCA2 in Fanconi anemia. Science. 2002;297:606-9.

16. Raya A, Rodriguez-Piza I, Guenechea G, et al. Disease-corrected haematopoietic progenitors from Fanconi anaemia induced pluripotent stem cells. Nature. 2009;460:53-9. 